\title{
Health and health care utilisation among asylum seekers and refugees in the Netherlands: design of a study
}

\author{
Annette AM Gerritsen*1,2, Inge Bramsen ${ }^{1,2}$, Walter Devillé3, Loes HM van \\ Willigen $^{4}$, Johannes E Hovens ${ }^{5}$ and Henk M van der Ploeg ${ }^{1,2}$
}

\begin{abstract}
Address: ${ }^{1}$ Department of Medical Psychology, VU University Medical Centre, Van der Boechorststraat 7, 1081 BT Amsterdam, The Netherlands, ${ }^{2}$ Institute for Research in Extramural Medicine, VU University Medical Centre, Van der Boechorststraat 7, 1081 BT Amsterdam, The Netherlands, ${ }^{3}$ Netherlands Institute for Health Services Research, P.O. Box 1568, 3500 BN Utrecht, The Netherlands, ${ }^{4}$ Consultancy for Health and Human Rights, Stuurmankade 336, 1019 WE Amsterdam, The Netherlands and 5 Delta Bouman Psychiatric Teaching Hospital, P.O. Box 800, 3170 DZ Poortugaal, The Netherlands

Email: Annette AM Gerritsen* - aam.gerritsen@vumc.nl; Inge Bramsen - i.bramsen@vumc.nl; Walter Devillé - w.deville@nivel.nl; Loes HM van Willigen - lvanwil@xs4all.nl; Johannes E Hovens - hanhov@deltabouman.nl; Henk M van der Ploeg - hm.vanderploeg@vumc.nl

* Corresponding author
\end{abstract}

Published: 10 March 2004

BMC Public Health 2004, 4:7
Received: II February 2004

Accepted: 10 March 2004

This article is available from: http://www.biomedcentral.com/I47/-2458/4/7

(C) 2004 Gerritsen et al; licensee BioMed Central Ltd. This is an Open Access article: verbatim copying and redistribution of this article are permitted in all media for any purpose, provided this notice is preserved along with the article's original URL.

\begin{abstract}
Background: This article discusses the design of a study on the prevalence of health problems (both physical and mental) and the utilisation of health care services among asylum seekers and refugees in the Netherlands, including factors that may be related to their health and their utilisation of these services.

Methods/Design: The study will include random samples of adult asylum seekers and refugees from Afghanistan, Iran and Somali (total planned sample of 600), as these are among the largest groups within the reception centres and municipalities in the Netherlands.

The questionnaire that will be used will include questions on physical health (chronic and acute diseases and somatization), mental health (Hopkins Symptoms Checklist-25 and Harvard Trauma Questionnaire), utilisation of health care services, pre- and post-migratory traumatic experiences, life-style, acculturation, social support and socio-demographic background. The questionnaire has gone through a translation process (translation and back-translation, several checks and a pilotstudy) and cross-cultural adaptation. Respondents will be interviewed by bilingual and bicultural interviewers who will be specifically trained for this purpose.

This article discusses the selection of the study population, the chosen outcome measures, the translation and cross-cultural adaptation of the measurement instrument, the training of the interviewers and the practical execution of the study. The information provided may be useful for other researchers in this relatively new field of epidemiological research among various groups of asylum seekers and refugees.
\end{abstract}

\section{Background}

In the Netherlands, health surveys are frequently conducted to assess the health of the population and the uti- lisation of health care services [1,2]. Due to language and cultural problems these surveys often exclude (first generation) immigrants. However, in recent years, much 
research has focused on the four largest immigrant groups, i.e. people from Surinam, the Netherlands Antilles, Turkey and Morocco [1,3]. Although refugees have been coming to the Netherlands since the eighties, their numbers were not large enough and their backgrounds were too diverse for them to be the subject of large-scale epidemiological research. However, it is important that research also focuses on these groups, which differ from the four largest immigrant groups because they migrated involuntarily and may have a history of loss and traumatic experiences. A differentiation can be made between refugees who have a residence permit, and asylum seekers who are still in uncertainty of achieving such a status. These two groups may also differ with regard to living arrangements, because most asylum seekers in the Netherlands live in reception centres. Both factors may cause differences in their health status and their utilisation of health care services, and therefore both groups should be studied. In general, the term 'refugees' will be used for both groups throughout the text, and the term 'asylum seekers' will only be used if a distinction between the groups is important.

Early research on refugees focused mainly on those refugees who consulted health care services [4]. This gave an indication of the kind of problems refugees experience, but not of the prevalence of disorders, because not all refugees have or seek medical care for health problems. Other studies focused specifically on the victims of torture, but again such people are not representative of the refugee population in general [5]. Most population-based studies focusing on adult refugees living in a Western country report on the prevalence of psychiatric diseases, mainly post-traumatic stress disorder (PTSD), depression and anxiety. There is a huge range in reported prevalence rates, due to the fact that the studies are very heterogeneous with respect to the study population (e.g. selection of the study population, country of origin, duration of residence in the country of resettlement, refugee status) and measurement instruments. For example, the prevalence rates for PTSD range from $4 \%$ to $70 \%$, and similar percentages are reported for the prevalence of depression $(3 \%$ to $88 \%$ ) and anxiety ( $2 \%$ to $80 \%$ ) (Table 1 ).

Furthermore, many factors related to the mental health of refugees are reported in the literature cited in Table 1: preand post-migratory traumatic experiences, proficiency in the language of the country of resettlement, social network, socio-demographic background, including gender, work status, duration of residence in the country of resettlement, and marital status.

Besides studies of the physical conditions detected shortly after the arrival of the refugees (e.g. infectious diseases) [6] and studies focusing on the physical sequelae of tor- ture, [7], few studies have investigated physical complaints such as gastrointestinal diseases, musculoskeletal complaints and cardiovascular diseases [8-12]. Moreover, the utilisation of health care services has not often been addressed in surveys [11-14].

Taking all this into account, it was decided to conduct a large-scale epidemiological study on the prevalence of health problems among both refugees and asylum seekers, including not only mental but also physical health problems, and their utilisation of health care services. In addition it is the intention to study several factors (traumatic experiences, life-style, acculturation, social support, socio-demographic background) that may be related to the health problems and the utilisation of these services. Unlike many of the other studies, the study will include refugees and asylum seekers from three different countries of origin. The aim of the study is to provide some basic epidemiological data on the health and health care utilisation among this population, and thereby improve the health care that is provided (in the Netherlands) for asylum seekers and refugees.

This article discusses the design of the study: selection of the study population, the chosen outcome measures, cross-cultural adaptation of the measurement instrument, training of the interviewers and the practical execution of the study. Papers reporting the study results can not elaborate much on these issues, although this information may be useful for other researchers in this relatively new field of research, in which problems related to differences in the language and background of the population have to be faced. Describing the design of this study may also help to enhance the comparability of future studies (e.g. regarding the choice of measurement instruments). Furthermore, it permits critical assessment of the methodological quality of the study, irrespective of the outcomes. This is important, because a study is more likely to be examined for methodological limitations if the results differ from what was expected than when the results are in line with the expectations.

The study design was approved by the Medical Ethics Committee of the VU University Medical Centre in Amsterdam.

\section{Methods/Design Study population}

On $1^{\text {st }}$ September 2002, the top 10 nationalities of residents in the Dutch reception centres were: Iraq $(8,445$ people), Afghanistan $(7,105)$, Angola $(6,140)$, former Yugoslavia $(4,806)$, Iran $(4,509)$, Azerbaijan $(4,398)$, Somalia $(3,888)$, Sierra Leone $(3,300)$, Sudan $(3,176)$ and Syria $(2,391)[15]$. Because it was also the intention to study refugees the number of first generation immigrants 
Table I: Prevalence of PTSD, depression and anxiety in population-based studies on refugees living in a Western country

\begin{tabular}{|c|c|c|c|c|c|}
\hline Reference & $\begin{array}{l}\text { Prevalence } \\
\text { PTSD }\end{array}$ & $\begin{array}{l}\text { Prevalence } \\
\text { depression }\end{array}$ & $\begin{array}{l}\text { Prevalence } \\
\text { anxiety }\end{array}$ & Measurement instrument & Study population \\
\hline$[13]$ & $4 \%$ & $3 \%$ & $5 \%$ & CIDI & $\begin{array}{l}\text { II } 6 \text { I Vietnamese refugees living on average II years } \\
\text { in Australia }\end{array}$ \\
\hline$[39,40]$ & $\begin{array}{l}4 \% \text { (and } 9 \% \\
\text { just after } \\
\text { arrival) }\end{array}$ & $18 \%$ & $2 \%$ & $\begin{array}{l}\text { criteria from the DSM- Third } \\
\text { Edition (PTSD) and Present State } \\
\text { Examination (depression and } \\
\text { anxiety) }\end{array}$ & $\begin{array}{l}\text { I } 45 \text { Vietnamese quota refugees interviewed } 3 \text { years } \\
\text { after resettlement in Norway }\end{array}$ \\
\hline$[10,41,42]$ & $11 \%$ & $4 \%$ & & $\begin{array}{l}\text { criteria from the DSM-Revised } \\
\text { Third Edition }\end{array}$ & $\begin{array}{l}86 \text { Iranian and } 70 \text { Turkish asylum seekers (5I\%) and } \\
\text { refugees living in reception centres }(62 \%) \text { in the } \\
\text { Netherlands ( } 70 \% \text { less than I year) }\end{array}$ \\
\hline$[43]$ & $12 \%$ & & & $\begin{array}{l}\text { Post-traumatic stress section of } \\
\text { the Diagnostic Interview } \\
\text { Schedule }\end{array}$ & $\begin{array}{l}223 \text { Cambodian refugees living } 3 \text { months to } 10 \text { years } \\
\text { in New Zealand }\end{array}$ \\
\hline$[24]$ & $15 \%$ & & & HTQ & $\begin{array}{l}240 \text { refugees, predominantly from former } \\
\text { Yugoslavia, interviewed on average } 10 \text { months and } 3 \\
\text { years after resettlement in Norway }\end{array}$ \\
\hline$[44]$ & $18-33 \%$ & $21 \%$ & & $\begin{array}{l}\text { modified version of the Post- } \\
\text { traumatic Symptom Scale (PTSD) } \\
\text { and a questionnaire (depression) }\end{array}$ & $\begin{array}{l}206 \text { refugees from Bosnia-Hercegovina living in an } \\
\text { asylum centre in Sweden }\end{array}$ \\
\hline [8] & $22 \%$ & & & HTQ & $\begin{array}{l}\text { I } 57 \text { refugees from Kosovo living on average } 2 \text { years } \\
\text { in Canada }\end{array}$ \\
\hline$[27]$ & $32 \%$ & $63 \%$ & $36 \%$ & $\begin{array}{l}\text { HTQ (PTSD) en HSCL-25 } \\
\text { (depression and anxiety) }\end{array}$ & $\begin{array}{l}54 \text { Somalian asylum seekers }(76 \%) \text { and refugees } \\
\text { living in reception centres ( } 65 \% \text { less than } 6 \text { months) } \\
\text { in the Netherlands }\end{array}$ \\
\hline$[45]$ & $35 \%$ & $57 \%$ & & CIDI & $\begin{array}{l}\text { 5I Afghan refugees living on average } 4 \text { years in the } \\
\text { Netherlands }\end{array}$ \\
\hline$[25]$ & $35 \%$ & $33 \%$ & $23 \%$ & $\begin{array}{l}\text { CIDI (PTSD) and HSCL-25 } \\
\text { (depression and anxiety) }\end{array}$ & $\begin{array}{l}40 \text { asylum seekers from } 21 \text { countries living on } \\
\text { average } 3 \text { years in Australia }\end{array}$ \\
\hline$[32]$ & $37 \%$ & & & CAPS & $\begin{array}{l}86 \text { Iraqi and Kurdish refugees recently resettled in } \\
\text { Sweden }\end{array}$ \\
\hline$[12]$ & $45 \%$ & $51 \%$ & & $\begin{array}{l}\text { Diagnostic Interview for Children } \\
\text { and Adolescents-revised (PTSD) } \\
\text { and National Institute of Mental } \\
\text { Health Diagnostic Interview } \\
\text { Schedule (depression) }\end{array}$ & $\begin{array}{l}124 \text { Cambodian refugees living on average } 8 \text { years in } \\
\text { the United States }\end{array}$ \\
\hline$[46]$ & $50 \%$ & & & $\begin{array}{l}\text { Structured Clinical Interview for } \\
\text { DSM-Fourth Edition }\end{array}$ & $\begin{array}{l}40 \text { refugees from former Yugoslavia living on } \\
\text { average } 3.5 \text { years in a refugee camp in Italy }\end{array}$ \\
\hline$[47]$ & $61 \%$ & & & PDS & $\begin{array}{l}129 \text { Kosovar refugees studied immediately upon } \\
\text { resettlement in the United States }\end{array}$ \\
\hline$[48]$ & $63 \%$ & & & CAPS & $\begin{array}{l}\text { I } 26 \text { Bosnian refugees with a permanent residency } \\
\text { status living for over } 3 \text { years }(92 \%) \text { in Australia }\end{array}$ \\
\hline$[49]$ & $65 \%$ & $44 \%$ & $34 \%$ & $\begin{array}{l}\text { PDS (PTSD) and Beck } \\
\text { Depression and Anxiety } \\
\text { Inventory }\end{array}$ & $\begin{array}{l}842 \text { refugees from Kosovo living in reception } \\
\text { centres in the United Kingdom }\end{array}$ \\
\hline [26] & $86 \%$ & $88 \%$ & $80 \%$ & $\begin{array}{l}\text { PTSD Checklist based on criteria } \\
\text { from the DSM-Revised Third } \\
\text { Edition and HSCL-25 (depression } \\
\text { and anxiety) }\end{array}$ & $\begin{array}{l}50 \text { Cambodian refugees living on average } 5 \text { years in } \\
\text { the United States }\end{array}$ \\
\hline$[50]$ & $70 \%$ & & & PDS & 4I Bosnian refugees living in the United States \\
\hline$[51]$ & & $\begin{array}{l}6 \% \text { (just } \\
\text { after } \\
\text { arrival) - } \\
2 \%(10 \\
\text { years after } \\
\text { arrival) }\end{array}$ & & symptom inventory & 608 Southeast Asian refugees living in Canada \\
\hline$[52]$ & & $25 \%$ & $25 \%$ & $\mathrm{HSCL}$ & $\begin{array}{l}\text { I } 80 \text { Somali refugees ( } 96 \%) \text { and asylum seekers living } \\
\text { on average } 8 \text { years in the United Kingdom }\end{array}$ \\
\hline [28] & & $29 \%$ & $15 \%$ & HSCL-25 & 129 Indochinese refugees living in New Zealand \\
\hline
\end{tabular}

CIDI = Composite International Diagnostic Interview; DSM = Diagnostic and Statistical Manual of Mental Disorders; HTQ = Harvard Trauma Questionnaire; CAPS = Clinician-Administered PTSD Scale; PDS = Posttraumatic Diagnostic Scale; HSCL = Hopkins Symptom Check List 
originating from these countries and living in the Nether-

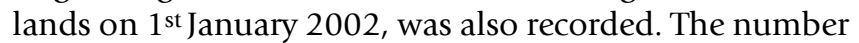
of immigrants from five countries was large enough to consider these nationalities for inclusion in the study: former Yugoslavia (55,760 people), Iraq $(35,918)$, Afghanistan (28,448), Iran $(22,998)$ and Somalia $(21,071)[16]$. For practical reasons (e.g. translation of the study materials, recruitment of interviewers) former Yugoslavia was not chosen, because this group includes several smaller groups with different ethnic backgrounds and different languages. Furthermore, Iraq was not chosen, because at that time a study on the mental health of asylum seekers from Iraq was being conducted by the Drenthe Mental Health Care Services in the Netherlands. Therefore, people from Afghanistan, Iran and Somalia will be included in this study. To make it possible to compare prevalence rates within sub-groups of people, the plan is to include 100 asylum seekers and 100 refugees per country of origin, resulting in a total study population of 600 people. To achieve a representative sample of all asylum seekers and refugees from these three countries, the sampling procedures described below were applied.

\section{Sample of asylum seekers}

Based on the mean number of asylum seekers from Afghanistan, Iran and Somalia per reception centre it was decided to include 15 centres in the study. For practical reasons (e.g. travel distances for the interviewers) these reception centres were randomly selected from the 46 centres located in the central region of the Netherlands. One centre was excluded from the sample because it was not considered to be representative. The Community Health Services for Asylum Seekers (MOA) had undergone radical changes due to some recent incidents concerning the health of asylum seekers living in the centre. The central administration of the Dutch Agency for the Reception of Asylum Seekers (COA) was asked to provide the contact details (names, addresses, dates of birth and gender) of all people originating from Afghanistan, Iran and Somalia who were living in the 14 centres. To be eligible for inclusion these people must be 18 years of age or older. Most of them will actually be staying in one of the reception centres concerned, but some might be living in a (neighbouring) municipality. Although most of them will not be in possession of a residence permit, some might be, but are still living in a centre because of lack of alternative accommodation. Because members of the same family may have similar values for some of the outcomes studied (e.g. traumatic experiences, social support), only one person per family was randomly selected for inclusion in the study on the basis of a registration code. This resulted in a sample of at least 157 people per country of origin from all 14 centres together.

\section{Sample of refugees}

Per country a list was made of municipalities in which at least 200 first generation immigrants originating from that country were living [16]. At that time, a study on the social status and utilisation of welfare facilities among refugees was being conducted by the Institute for Sociological and Economic Research at the Erasmus University Rotterdam - which also included refugees from Afghanistan, Iran and Somalia - so it was decided not to approach the same municipalities. Furthermore, municipalities were only taken into consideration if they agreed to provide the names and addresses of the people in the sample, so that they could be contacted directly. Some of the municipalities wanted to contact these people themselves and ask for permission to pass on their contact details, but it was thought that this would lower the response rate. Three municipalities (Leiden, Zaanstad and Arnhem) were finally approached and asked to provide a random sample from the population register of 100-150 people per country of origin. Criteria for inclusion in the sample were: 18 years of age or older; born in Afghanistan, Iran or Somalia (or if the country of birth was not recorded, at least one parent born in one of these countries); in possession of a residence permit or the Dutch nationality. Finally, a randomly selection was made of one person per address for inclusion in the study, leaving at least 62 people per country of origin in the sample from each municipality.

\section{Outcome measures}

A recently conducted systematic review described the cross-cultural validity and reliability of instruments measuring refugee trauma and health status [17]. The present study included some of the instruments that had either been developed for, or adapted and tested in refugee research (e.g. Harvard Trauma Questionnaire (HTQ), Hopkins Symptom Check List-25 (HSCL-25), 90-item Symptom Check List (SCL-90)). However, the validity and reliability of these instruments has not been tested in the population included in the present study. Furthermore, no cut-off scores for symptomatic status have been established for this population. This should be taken into account when interpreting the results of this study. If no instruments that had been used in refugee research were available questions used in health surveys among the Dutch general or immigrant population were used. However, the cross-cultural validity and reliability of these questions has not been tested.

A draftversion of the questionnaire was discussed with key-informants (males and females) who were refugees from Afghanistan (3), Iran (5) and Somalia (4). They were contacted with the help of refugee organisations and via the snowballmethod, and had different professional backgrounds (e.g. anthropologist, physician, social worker). 
They were asked to give their opinion about the items on the questionnaire and the phrasing of the questions. This version of the questionnaire was also reviewed by more than 20 professionals working with refugees (e.g. anthropologists, epidemiologists, physicians, psychologists). The questionnaire was modified with the help of the comments on the draftversion. Questions related to sexual behaviour were omitted (e.g. sexually transmitted diseases, female genital mutilation), because this subject was considered to be taboo, and the answers were expected to be unreliable. The same was thought to apply to questions concerning the use of drugs. A qualitative study design might be more suitable to investigate these issues $[18,19]$. Certain background variables were also omitted (e.g. reason for requesting asylum in the Netherlands, ethnic origin), because these questions might remind the respondents too much about the Immigration and Naturalisation Service (IND) interrogations, and might therefore have a negative influence on the respondents confidence in the interviewer. Furthermore, specific response items were added for some questions, because of the cultural or refugee background of the respondents: e.g. traditional healers and medications, and specific daily activities of asylum seekers living in reception centres (because they are not allowed to work, they spent a lot of time watching television, participating in sports, etc.). The final version of the questionnaire included the outcome measures described below.

\section{Health}

General

The current health status of respondents was measured according to the general health question on the 36-item Short-Form [20]. The response options ranged from ' $5=$ excellent' to ' 1 = poor'. This item has been used in health surveys among the general and immigrant population of the Netherlands $[1,2]$.

Furthermore, respondents were asked to mention their main health complaints and what they thought to be the cause of these complaints (e.g. physical or mental problem, the situation in the country of origin or in the Netherlands).

\section{Physical health}

The respondents were asked to indicate for 28 chronic conditions whether or not they had had this condition in the previous 12 months. If so, they were asked if they had visited or been treated by a doctor for this condition during this period. The list of chronic conditions included the items in the national health surveys (e.g. cardiovascular diseases; pulmonary diseases). Furthermore, some items from the screening list used by the MOA were added (e.g. tuberculosis; hepatitis). In addition, seven acute diseases (e.g. flu; bladder infection) from the same surveys were included. Respondents were asked to indicate whether or not they had had these diseases in the previous two months and, if so, whether they had visited a general practitioner for their complaints. Respondents could also mention a chronic or acute disease that was not included in the list.

Possible somatisation was measured according to the somatic complaints sub-scale of the SCL-90-Revised [21]. This scale consists of 12 items (e.g. pain in the heart or chest; pain in the lower back) which are complaints that may not be explained by the presence of physical illness, but might be caused by severe stress. Items could be scored on a 5 -point scale, ranging from ' $1=$ not at all' to ' 5 = extremely' bothered by the complaint in the previous week. The sum of all responses divided by the number of items answered produces a mean score. Seven groups are used to classify these mean scores (from 'very high' to 'very low'). This somatisation sub-scale has been used in a population survey of the psychosocial adjustment of Hmong refugees living in the United States [22].

\section{Mental health}

The HSCL-25 was used to measure symptoms of anxiety (10 items, e.g. suddenly scared for no reason; feeling fearful) and depression (15 items, e.g. blaming yourself for things; crying easily) [23]. Respondents were asked to indicate the extent to which they were bothered by each symptom in the previous week, ranging from ' 1 = not at all' to ' 4 = extremely'. Individuals with a mean score for anxiety and/or depression and/or the total list of symptoms $>1.75$ are considered to be symptomatic. The scale has been used in several refugee studies [10,24-28]. Because an earlier study on symptoms of depressive illness concluded that the majority of Afghan patients will express death wishes rather than suicidal thoughts, this item was added to the list [29]. Two items describing typical syndromes of distress related to depression and anxiety in the Iranian culture were also added to the Farsiversion of the questionnaire: nârâhati-e qalb (distress of the heart) and nârâhati-e a'sâb (distress of the nerves) [30].

Part IV of the HTQ was used to measure PTSD [31]. It includes 30 symptoms, the first 16 of which were derived from the Diagnostic and Statistical Manual of Mental Disorders-Revised Third Edition (DSM-III-R) criteria for PTSD (e.g. feeling as though the event is happening again; recurrent nightmares). The other 14 items describe symptoms related to the traumatic life events of (Indochinese) refugees (e.g. difficulty in performing work or daily tasks; blaming yourself for things that have happened). The format of the response options is comparable to that of the HSCL-25. Individuals with a mean score on the 16 PTSD symptoms and/or on the total list of 30 symptoms $\geq 2.5$ 
are considered to be symptomatic for PTSD. This scale has also been used in many studies on refugees $[8,24,27]$.

An attempt was made to identify culture-specific symptoms of anxiety, depression and trauma by giving respondents the opportunity to mention symptoms that were not included in the list.

\section{Utilisation of health care services}

The following data were recorded: 1) frequency of contact with a general practitioner, outpatient medical specialist, dentist, physiotherapist, nurse and social-physician of the MOA, in the previous two months; 2) hospital admissions, contacts with mental health services (e.g. psychologist, psychiatrist), contacts with alternative practitioners (e.g. acupuncturist, homoeopathist), in the previous year; 3 ) use of health care services in the country of origin or other foreign countries in the previous year, and the reason for not using the Dutch health care services; 4) use of (un)prescribed medication in the previous 14 days and type of medication. Some of these measures are also used in the national health surveys. Furthermore, respondents were asked about: who they would turn to with their health problems, their expectations with regard to the Dutch health care providers, their opinion on the Dutch health care system (ranging from ' $5=$ excellent' to ' $1=$ poor') and the reason for this opinion, and suggestions for possible improvements in this system.

\section{Traumatic experiences}

First the respondents were asked about possible stressful experiences they had had in the Netherlands. The checklist included 18 problems often reported by refugees in research on post-migratory stressors (e.g. delays in the application for a residence permit; loneliness) [10,25,32]. They were asked to indicate the extent to which any of the items had bothered them in the previous month (' $1=$ not at all' to ' $4=$ extremely'). Furthermore, they were given the opportunity to mention items that were not included in the list.

Other traumatic experiences were assessed with part I of the HTQ, which includes 17 events (e.g. lack of food and water; being close to death) [31]. There were four possible responses for each event (experienced, witnessed, heard about it or no) and respondents were asked to check all that were applicable. Responses are summed and divided by the number of items answered to generate two scores: total number of events (sum of all items for which the response differs from 'no') and total number of events experienced (sum of all items with a positive response to 'experienced'). However, the score for 'total number of events' often approached the maximum score of 17 , due to the fact that almost everybody at least answered 'heard about it' to all items. Therefore, the response scale was replaced with a simple yes/no (experienced) option in later versions, because empirical evidence revealed the primary importance of the number of experienced events. Because being a witness can also be an important traumatic event, it was decided to use the earlier response scale, but to eliminate the response 'heard about'. However, this should still make it possible to compare the results of the study with those of other studies which used either the earlier or the later version $[13,25,27,33]$. Furthermore, the list was extended to include 15 other traumatic events, specially relevant to people from Afghanistan, Iran and Somalia, which were selected from Amnesty International Annual Reports (1975-2002) (e.g. rocket attacks, bombardments; confiscation or destruction of houses, crops, water supply). Also included was part III of the HTQ focussing on four traumatic events (yes/no experienced) that may involve head injury (e.g. drowning, suffocation).

Finally, the respondents were asked to indicate those events that they considered to be the most traumatic events that they had experienced in the Netherlands, in their country of origin or during their flight, and in their whole life.

\section{Life-style}

Different aspects of life-style were measured as follows: 1) Body mass index (BMI) was calculated by dividing selfreported body weight $(\mathrm{kg})$ by height squared $\left(\mathrm{m}^{2}\right)$. Overweight is defined as a BMI of $25-30 \mathrm{~kg} / \mathrm{m}^{2}$ and obesity as a BMI of $30 \mathrm{~kg} / \mathrm{m}^{2}$ or more. 2) Physical activity was assessed by asking respondents how many days a week they spent at least half an hour on physical activities in relation to work, school, household and leisure. According to Dutch standards for adults, this should be at least five days a week. 3) Smoking behaviour was assessed by asking respondents whether they smoked, and if so, how much tobacco they smoked. Heavy smoking is defined as smoking 20 or more cigarettes a day. 4) Alcohol consumption was assessed by asking respondents whether they drank alcohol, and if so, how often they had six or more alcoholic drinks on one occasion. Heavy drinking is defined as having six or more alcoholic drinks at least once a weak. All these life-style measures are used in the national health surveys.

\section{Acculturation}

To measure the level of self-rated acculturation of the respondents a list of questions was compliled, including items that had already been used in other studies $[1,34]$. No established acculturation measure was used, because most of the scales are developed for specific groups of immigrants, and take into account the history and conditions of their migration. As a consequence, these scales include items that are not applicable to refugees from Afh- 
anistan, Iran and Somalia. The nine questions in the list focused on: self-reported proficiency (understanding, speaking, reading, writing) in the native language, Dutch and English ('not at all', 'a little', 'sufficient', 'good'); use of language in various situations; food preferences; feeling at home in the Netherlands; which to return home; and ethnic identity (e.g. 'mainly Dutch', 'both Dutch and Afghan').

\section{Social support}

With regard to social support, two issues were taken into consideration: the frequency of contacts with people who may provide social support, and the perceived amount of support received. To assess the first aspect, respondents were asked about the contact frequency ('often', 'sometimes', 'never') with other people (e.g. family or friends, both in the Netherlands or elsewhere) and with whom they had the most frequent contact. To measure the perceived amount of support received, the established social support measures were not considered to be useful, because they do not take into account the particular life situation of refugees and asylum seekers (e.g. separated from family and friends, living in a reception centre). Therefore, four items were selected from the Social Support Scale (SOS) [35] (e.g. If I have problems there are people I can turn to) and two items from the UCLA Loneliness scale [36] (e.g. There are people who really understand me). Respondents were asked to indicate whether or not these statements applied to them ('yes', 'no') in the previous month.

\section{Socio-demographic background}

The following socio-demographic variables were recorded: gender; age; country of origin; residence permit ('no [application rejected or application under review]', 'temporary', 'permanent' or 'Dutch nationality'); period of residence in the Netherlands and, if applicable, time since obtaining a residence permit (to calculate the duration of the asylum procedure); highest level of education completed; marital status; number and age of children; whereabouts of spouse and any children; main daily activities; and religion.

\section{Questionnaire translation}

Taking into account the available resources (time and finance), published guidelines were adhered to as possible for the cross-cultural adaptation of the questionnaire $[37,38]$. The entire process took approximately five months. The first step was to translate the questionnaire from the original language (Dutch) into the target languages (Dari and Pashto - Afghan languages, Farsi - Iranian language, and Somali), and this was done by experienced translators. Working from the translated version of the questionnaire and totally unaware of the original version, other experienced translators then translated the questionnaire back into the original language. All discrepancies between the original Dutch questionnaire and the back-translated version were recorded by a researcher, who was not familiar with the target languages, and the two translators. These discrepancies were then discussed item-by-item and resolved by consensus. Accordingly, corrections were made, and checked again, which resulted in a second version of the translation. It was found to be important that the researcher made it clear to both translators that discussing discrepancies was in no way meant to judge their work, but to make sure that the translated version was reflecting exactly the same content as the original version. Because also a Dutch version of the questionnaire was needed, the same translation process was also followed for the HTQ, for which no Dutch translation was available.

In general, it was found that it was possible to translate most items. However, in all languages there were some terms for which no translation was available: for example some chronic diseases (e.g. pulmonary emphysema, slipped disc, angina pectoris), different types of alternative practitioners (e.g. chiropractor, paranormal healer) and the word 'traumatic'. In such cases a description was given and/or the Dutch word was added (between brackets). Furthermore, some phrases were at first translated literally whereas they were meant to be metaphorical (e.g. 'difficulties with breathing' instead of 'shortness of breath'; 'fever or cold' instead of 'hot or cold spells'). Some expressions (e.g. 'feeling on guard', 'my social relationships are superficial') were so difficult to translate that an item with a similar meaning had to be found. In some cases, items had to be substituted by others, because they did not apply to the study population (e.g. 'gardening' was replaced by 'walking' in the question on physical activities, because gardening is not something that asylum seekers do in a reception centre). Finally, there were some difficulties in the translation of large categories of ordinal responses (e.g. the differences between the five response categories of the SCL-90-R). The experienced translators also translated all other study materials (introduction letter, confidentiality statement, etc.).

\section{Interviewer recruitment and training}

Although the questionnaire can be self-administered, it was decided to make use of bilingual interviewers from the three countries of origin. This was expected to result in a higher response rate, because many respondents might not be familiar with surveys, and some may have difficulties in reading and writing. Furthermore, interviewers could explain the purpose of the study in the respondent's own language and (cultural and refugee) context, thus minimising the risk of misunderstanding or miscommunication. 
An advertisement to recruit interviewers was distributed twice among refugee organisations, employment agencies (for refugees), key-informants, professionals working with refugees, and translators and over a 100 written applications were received. The applicants were screened on interview experience and/or relevant education and/or working experience with refugees, and approximately 65 eligible people were invited for a personal interview. Those with good communication and social skills were selected to participate in a two-day training session. A total of 33 interviewers were trained ( 9 Afghan -5 females and 4 males, 15 Iranian - 11 females and 4 males and 9 Somalian - 4 females and 5 males). Most of the interviewers were students studying (para)medical or social subjects. Before the training all participants received a manual in which the content of the interview training was described. The first day of the training included an introduction to the study (background information, purpose, design), general interviewing skills and techniques (e.g. types of questions; adherence to question sequence and wording), and an explanation of the meaning of all items and response options on the questionnaire, which took place while the interview was being practised in the group. There was some role-playing in which specific situations and problems that interviewers could encounter in actual interviews were simulated (e.g. how to keep the respondent 'on track' when he or she wanders off the subject; how to deal with a respondent who is becoming emotional). On the second day the participants practised the interview in pairs in their own language. Furthermore, they practised contact procedures, introducing and ending the interview (including answering frequently asked questions and reacting to typical objections from respondents with regard to co-operation). After completing the training the interviewers could start contacting the first set of five respondents. After each set of interviews, written feedback was given to the interviewers with regard to the quality of the interviews. A researchassistant also has regular contact by phone and (e-)mail with the interviewers to monitor their progress and discuss any problems that may arise.

During the first training sessions, considerable time was spent discussing the quality of the translation of the questionnaire. Several changes were suggested to the translators, which resulted in a third version. After that training session the questionnaire and the interview procedures were pre-tested. Interviewers were instructed to record any difficulties they encountered and, for example, the time they needed to complete the interview. These difficulties were discussed during an afternoon session. As a result of the pilot study, some minor changes were made in the translation of the questionnaire. In total, 12 respondents were contacted in a reception centre which was not included in the main study. Of these, 9 were interviewed and the other 3 were unwilling to participate for various reasons. In the three municipalities 18 respondents were contacted, only 6 of whom were interviewed. The main reasons for not interviewing a respondent were: the respondent was not living at the given address; the respondent had not come to the Netherlands as a refugee; other reasons for not wanting to participate in the study.

\section{Procedures}

Persons selected for inclusion in the study are sent a letter, both in Dutch and in the language(s) of their country of origin, informing them about the study and announcing that an interviewer will contact them for an interview. If possible respondents will be contacted by phone, otherwise a visit will be paid to the respondent's house or room in the reception centre. If the respondent is not at home a note is left with contact details and the date and time when the interviewer will try to contact the respondent again. The interviewers are instructed to try to contact a respondent three times and all attempts are recorded. If the respondents are contacted they are told about the type of questions they can expect and about the voluntary nature of participation. Asylum seekers are assured that participation in the study will neither help nor hinder their request for asylum, in an attempt to prevent them from participating for the wrong reasons and exaggerating their problems in order to obtain a residence permit. Reasons for not completing an interview with a respondent (e.g. the respondent was never at home; the respondent was not interested in participating) are recorded by the interviewers. Respondents who are willing to participate in the study are given a statement in which the researcher and the interviewer guarantee, among other things, the strict confidentiality of responses and the anonymous reporting of the data. The reason why the respondents are not asked to sign an informed consent statement is that this may remind them of earlier confrontations with authorities. An attempt is made to have male interviewers for male respondents, and female interviewers for female respondents, and the interviews are held either in Dutch or in the respondent's native language. The interviews are estimated to take an average of 90 minutes. At the end of each interview the respondents are given the opportunity to ask questions and informed that a psychologist or physician with experience on PTSD is available if they wish to talk about any distressing feelings evoked by the interview. This service is also available for the interviewers, because they might find it difficult to listen to stories from the respondents, especially if they have experienced similar events themselves. The respondents are also asked to give written permission to the researchers to review their medical records (of the MOA and/or their general practitioner) and those of one of their children under the age of 18 (if applicable). In the second part of the study, which is conducted by the Netherlands Institute for Health Serv- 
ices Research (NIVEL) in Utrecht, the information on health problems and the utilisation of health care services from these records will be compared with the selfreported data obtained from the interviews. Finally, all respondents receive a financial incentive (10 euros).

\section{Discussion}

When conducting a population-based study among asylum seekers and refugees it is important that a representative sample is included. We plan to achieve this by using random sampling procedures for retrieving contact details of potential respondents and by taking various measures to minimise non-response: contacting respondents both by letter and in person, trying to reach a respondent several times, using bilingual and bicultural interviewers who can explain the purpose of the study and the questionnaire in the respondent's own language and cultural and refugee context, using an oral informed consent procedure, and giving a financial incentive.

When choosing the methods to obtain data, measurements instruments that have been found to be valid and reliable in the cultures included in the study, or at least in other refugee populations, should first be considered. If the cross-cultural validity and reliability of the instruments is unknown, this should be taken into account when interpreting the study results. Crioss-cultural adaptation of the chosen measurement instruments is a prerequisite if this has not already taken place; translation and back-translation only is not sufficient. In this study, certain checks were included, e.g. the interview training and the pilot-study, after which several amendments were made in the translation. Furthermore, based on the available literature on expressions of symptoms in various cultures, key-informants and professionals, some items were omitted from the questionnaire while certain specific questions and response options were added.

\section{Competing interests}

None declared

\section{Authors' contributions}

All authors participated in the design of the study. AG coordinated the study and drafted the manuscript. All authors read the drafts of the manuscript and approved the final version.

\section{Acknowledgements}

We whish to thank all refugee organisations, key-informants, professionals working with refugees, translators and interviewers who helped us with the cross-cultural adaptation of the measurement instrument and the interview procedures. We also thank the participating municipalities, the Dutch Agency for the Reception of Asylum Seekers (COA) and the Community Health Services for Asylum Seekers (MOA) for providing us with contact details of the respondents and helping us with the practical execution of the study. The research for this article was funded by the Netherlands Organisation for Health Research and Development (project number 2100.0097 ).

\section{References}

I. Schellevis FG, Westert GP, de Bakker DH, Groenewegen PP, van der Zee J, Bensing JM: De Tweede Nationale Studie naar ziekten en verrichtingen in de huisartsenpraktijk: aanleiding en methoden. Huisarts en Wetenschap 2003, 46:7-I2.

2. Netherlands Statistics: Permanent Survey on Living Conditions (POLS) Heerlen/Voorburg; 2002.

3. Reijneveld SA: Reported health, lifestyles, and use of health care of first generation immigrants in the Netherlands: do socioeconomic factors explain their adverse position? J Epidemiol Community Health 1998, 52:298-304.

4. Keyes EF: Mental health status in refugees: an integrative review of current research. Issues Ment Health Nurs 2000, 2l:397-4l0.

5. Basoglu M, Jaranson JM, Mollica R, Kastrup M: Torture and mental health. A research overview. The mental health consequences of torture Edited by: GerrityE, KeaneTM and TumaF. New York, Kluwer Academic/Plenum Publishers; 2001:35-62.

6. Ackerman LK: Health problems of refugees. J Am Board Fam Pract 1997, 10:337-348.

7. Moreno A, Grodin MA: Torture and its neurological sequelae. Spinal Cord 2002, 40:213-223.

8. Redwood-Campbell L, Fowler N, Kaczorowski J, Molinaro E, Robinson $S$, Howard M, Jafarpour M: How are new refugees doing in Canada? Comparison of the health and settlement of the Kosovars and Czech Roma. Can J Public Health 2003, 94:38I-385.

9. Sinnerbrink I, Silove D, Field A, Steel Z, Manicavasagar V: Compounding of premigration trauma and postmigration stress in asylum seekers. J Psychol 1997, I 3 I:463-470.

10. van Willigen LH, Hondius AJ, van der Ploeg HM: Health problems of refugees in The Netherlands. Trop Geogr Med 1995, 47:118-124.

II. Cheung P, Spears G: Illness aetiology constructs, health status and use of health services among Cambodians in New Zealand. Aust N Z J Psychiatry 1995, 29:257-265.

12. Blair RG: Risk factors associated with PTSD and major depression among Cambodian refugees in Utah. Health Soc Work 2000, 25:23-30.

13. Steel Z, Silove D, Phan T, Bauman A: Long-term effect of psychological trauma on the mental health of Vietnamese refugees resettled in Australia: a population-based study. Lancet 2002, 360:1056-1062.

14. Strand PJ, Jones W.,Jr.: Health service utilization by Indochinese refugees. Med Care 1983, 2 I: 1089-1098.

15. Service Immigration and Naturalisation: Rapportage vreemdelingenketen mei - augustus 2002 The Hague; 2002.

16. Netherlands Statistics: Statline Heerlen/Voorburg; 2002.

17. Hollifield M, Warner TD, Lian N, Krakow B, Jenkins JH, Kesler J, Stevenson J, Westermeyer J: Measuring trauma and health status in refugees: a critical review. JAMA 2002, 288:6 I I-62I.

18. Bartels K, Haaijer I: Vrouwenbesnijdenis en Somalische vrouwen in Nederland. Utrecht, Pharos; 1995.

19. Braam R, Dupont H, Verbraeck H: Asielzoekers en middelgebruik Utrecht, Centrum voor Verslavingsonderzoek; 1999.

20. McHorney CA, Ware J.E.,Jr., Raczek AE: The MOS 36-Item ShortForm Health Survey (SF-36): II. Psychometric and clinical tests of validity in measuring physical and mental health constructs. Med Care 1993, 31:247-263.

21. Arrindel WA, Ettema JHM: SCL-90. Handleiding bij een multidimensionele psychopathologie-indicator Lisse, Swets \& Zeitlinger; 2003.

22. Westermeyer J, Neider J, Callies A: Psychosocial adjustment of Hmong refugees during their first decade in the United States. A longitudinal study. J Nerv Ment Dis 1989, I 77:I32-I39.

23. Mollica RF, Wyshak G, de Marneffe D, Tu B, Yang T, Khuon F, Coelho RC, Lavelle J: Hopkins Symptoms Checklist 25 (HSCL-25): manual Cambodian, Laotian and Vietnamese versions. Torture 1996, 6 (Suppl. I):35-42.

24. Lie B: A 3-year follow-up study of psychosocial functioning and general symptoms in settled refugees. Acta Psychiatr Scand 2002, 106:415-425.

25. Silove D, Sinnerbrink I, Field A, Manicavasagar V, Steel Z: Anxiety, depression and PTSD in asylum-seekers: assocations with 
pre-migration trauma and post-migration stressors. $\mathrm{Br} \mathrm{J}$ Psychiatry 1997, 170:35I-357.

26. Carlson EB, Rosser-Hogan R: Mental health status of Cambodian refugees ten years after leaving their homes. $\mathrm{Am} \mathrm{J}$ Orthopsychiatry 1993, 63:223-231.

27. Roodenrijs TC, Scherpenzeel RP, de Jong J-TV-M: [Traumatic experiences and psychopathology among Somalian refugees in the Netherlands.]. Tijdschrift voor Psychiatrie 1998, 40:132-I 42.

28. Pernice R, Brook J: Relationship of migrant status (refugee or immigrant) to mental health. Int J Soc Psychiatry 1994, 40:177-188.

29. Waziri R: Symptomatology of depressive illness in Afghanistan. Am J Psychiatry 1973, 130:213-217.

30. Good BJ, DelVecchio Good MJ, Moradi R: The interpretation of Iranian depressive illness and dysphoric affect. Culture and depression Edited by: KleinmanA and GoodB. Berkeley/Los Angeles, University of California Press, Ltd.; 1985:369-428.

31. Mollica RF, Caspi-Yavin Y, Lavelle J, Tor S, Yang T, Chan S, Pham T, Ryan A, de Marneffe D: Harvard Trauma Questionnaire (HTQ): manual Cambodian, Laotian and Vietnamese versions. Torture 1996, 6 (Suppl. I): 19-33.

32. Sondergaard HP, Ekblad S, Theorell T: Self-reported life event patterns and their relation to health among recently resettled Iraqi and Kurdish refugees in Sweden.J Nerv Ment Dis 200I, 189:838-845.

33. van den Heuvel WJ: Health status of refugees from former Yugoslavia: descriptive study of the refugees in the Netherlands. Croat Med J 1998, 39:356-360.

34. van den Reek EWA: Somaliers en integratie - een profielschets Tilburg University; 200I.

35. Feij JA, Doorn CD, van Kampen D, van den Berg P.T.,Resing,W.C.M.: Sensation seeking and social support as moderators of the relationship between life events and physical illness/psychological distress. Lifestyles stress and health Edited by: Winnubst/AM and MaesS. Leiden, DSWO Press; 1992:285-302.

36. Russell DW: UCLA Loneliness Scale (Version 3): reliability, validity, and factor structure. J Pers Assess 1996, 66:20-40.

37. Beaton DE, Bombardier C, Guillemin F, Ferraz MB: Guidelines for the process of cross-cultural adaptation of self-report measures. Spine 2000, 25:3186-3191.

38. Bullinger M, Alonso J, Apolone G, Leplege A, Sullivan M, Wood-Dauphinee S, Gandek B, Wagner A, Aaronson N, Bech P, Fukuhara S, Kaasa $S$, Ware J.E.,Jr.: Translating health status questionnaires and evaluating their quality: the IQOLA Project approach. International Quality of Life Assessment. J Clin Epidemiol 1998, 5 I:913-923

39. Hauff E, Vaglum P: Chronic posttraumatic stress disorder in Vietnamese refugees. A prospective community study of prevalence, course, psychopathology, and stressors. J Nerv Ment Dis 1994, 182:85-90.

40. Hauff E, Vaglum P: Organised violence and the stress of exile. Predictors of mental health in a community cohort of Vietnamese refugees three years after resettlement. $\mathrm{Br}$ 」 Psychiatry 1995, 166:360-367.

41. Hondius AJK, van Willigen LHM: Vluchtelingen en gezondheid. Deel II: Empirisch onderzoek. Lisse, Swets \& Zeitlinger; 1992.

42. van Willigen LHM, Hondius AJK: Vluchtelingen en gezondheid. Deel I: Theoretische beschouwingen. Lisse, Swets \& Zeitlinger; 1992.

43. Cheung P: Posttraumatic stress disorder among Cambodian refugees in New Zealand. Int J Soc Psychiatry 1994, 40:17-26.

44. Thulesius $\mathrm{H}$, Hakansson A: Screening for posttraumatic stress disorder symptoms among Bosnian refugees. J Trauma Stress 1999, I 2:167-174.

45. Gernaat HB, Malwand AD, Laban C], Komproe I, de Jong JT: [Many psychiatric disorders in Afghan refugees with residential status in Drenthe, especially depressive disorder and post-traumatic stress disorder]. Ned Tijdschr Geneeskd 2002, 146: I|27-||3|.

46. Favaro A, Maiorani M, Colombo G, Santonastaso P: Traumatic experiences, posttraumatic stress disorder, and dissociative symptoms in a group of refugees from former Yugoslavia. J Nerv Ment Dis 1999, 187:306-308.

47. Ai AL, Peterson C, Ubelhor D: War-related trauma and symptoms of posttraumatic stress disorder among adult Kosovar refugees. J Trauma Stress 2002, I5:157-160.
48. Momartin S, Silove D, Manicavasagar V, Steel Z: Dimensions of trauma associated with posttraumatic stress disorder (PTSD) caseness, severity and functional impairment: a study of Bosnian refugees resettled in Australia. Soc Sci Med 2003, 57:775-78I.

49. Turner SW, Bowie C, Dunn G, Shapo L, Yule W: Mental health of Kosovan Albanian refugees in the UK. Br J Psychiatry 2003, 182:444-448.

50. Weine SM, Razzano L, Brkic N, Ramic A, Miller K, Smajkic A, Bijedic Z, Boskailo E, Mermelstein R, Pavkovic I: Profiling the trauma related symptoms of Bosnian refugees who have not sought mental health services. J Nerv Ment Dis 2000, 188:416-42I.

51. Beiser M, Hou F: Language acquisition, unemployment and depressive disorder among Southeast Asian refugees: a 10 year study. Soc Sci Med 200I, 53:I32I-I334.

52. Bhui K, Abdi A, Abdi M, Pereira S, Dualeh M, Robertson D, Sathyamoorthy $\mathrm{G}$, Ismail $\mathrm{H}$ : Traumatic events, migration characteristics and psychiatric symptoms among Somali refugees-preliminary communication. Soc Psychiatry Psychiatr Epidemiol 2003, 38:35-43.

\section{Pre-publication history}

The pre-publication history for this paper can be accessed here:

http://www.biomedcentral.com/1471-2458/4/7/prepub

Publish with BioMed Central and every scientist can read your work free of charge

"BioMed Central will be the most significant development for disseminating the results of biomedical research in our lifetime."

Sir Paul Nurse, Cancer Research UK

Your research papers will be:

- available free of charge to the entire biomedical community

- peer reviewed and published immediately upon acceptance

- cited in PubMed and archived on PubMed Central

- yours - you keep the copyright 